\title{
ANALISIS USAHA DAN PEMASARAN GULA SEMUT DI DESA HARGOTIRTO, KECAMATAN KOKAP, KABUPATEN KULON PROGO
}

\author{
Mega Nugraheni Apriza Putri*, Raden Kunto Adi, Isti Khomah
}

Program Studi Agribisnis, Fakultas Pertanian, Universitas Sebelas Maret

Jl. Ir. Sutami 36 A Kentingan Surakarta 57126

*Corresponding author: megaapriza@ student.uns.ac.id

\begin{abstract}
Crystal coconut sugar is an innovative product from processing coconut palm in the powder or granular form that have a yellow to brown colour. About 433,820 $\mathrm{kg}$ of crystal coconut sugar made in Hargotirto Village. The aim of this research is to analyze the cost, revenue, income, marketing cost, benefit cost, marginal marketing, and marketing efficiency economically in Hargotiro Village. The sample area is chosen by purposive sampling. The 93 respondents were taken by random sampling. Furthermore, snowball sampling was applied to take marketing channel respondents. The data analysis used is the cost analysis, revenue, income, marketing cost, benefit cost, and marginal marketing. The result of the research business analysis shows that are total rate revenue of crystal coconut sugar Rp51,360.22. There are three patterns of marketing channel of crystal coconut sugarin Hargotirto Village. Total benefit for each marketing channel is Rp7,640.39, Rp7,343.56, and Rp9,960.95. Total Marginal marketing for each marketing channel is Rp6,636.36, Rp5,000.00, and Rp4,840.91. Farmer's share for each marketing channel is $72,35 \%, 77,99 \%$, and $78,20 \%$, respectively.
\end{abstract}

Keywords: income of crystal coconut sugar, marketing channel, marginal marketing, farmer's share

\begin{abstract}
Abstrak: Gula semut adalah produk inovatif dari pengolahan nira kelapa dalam bentuk bubuk atau butiran bewarna kuning sampai cokelat. Sebanyak $433.820 \mathrm{~kg}$ produksi gula semut dibuat di Desa Hargotirto. Penelitian bertujuan untuk menganalisis pendapatan usaha, pola saluran pemasaran, biaya, keuntungan, marjin pemasaran, dan efisiensi pemasaran secara ekonomi masing-masing saluran pemasaran di Desa Hargotirto. Metode penentuan lokasi secara purposive. Sebanyak 93 responden diperoleh secara random. Pengambilan responden saluran pemasaran dengan teknik snowball sampling. Analisis data yang digunakan adalah analisis usaha dan analisis pemasaran. Analisis usaha meliputi analisis biaya, penerimaan, pendapatan usaha. Analisis pemasaran meliputi saluran pemasaran, biaya pemasaran, keuntungan pemasaran, dan marjin pemasaran. Hasil penelitian menunjukkan bahwa rata-rata penerimaan sebesar Rp51.366,22 per satu kali produksi. Terdapat tiga pola saluran pemasaran di Desa Hargotirto. Total keuntungan pemasaran masing-masing saluran pemasaran yaitu Rp7.640,39, Rp7.343,56, dan sebesar Rp9.960,95. Total marjin pemasaran pada masingmasing saluran yaitu Rp6.636,36, Rp5.000,00, dan Rp4.849,91. Nilai farmer's share untuk masing-masing saluran pemasaran yaitu 72,35\%, 77,99\%, dan 78,20\%.
\end{abstract}

Kata Kunci: pendapatan usaha, saluran pemasaran, marjin pemasaran, farmer's share

\section{PENDAHULUAN}

Sektor pertanian di Indonesia memiliki beberapa subsektor yang terdiri dari subsektor tanaman pangan, subsektor perkebunan, subsektor peternakan, dan subsektor kehutanan. Dari sektor-sektor pertanian tersebut, subsektor perkebunan merupakan salah satu subsektor yang mengalami pertumbuhan paling konsisten. Pengembangan subsektor perkebunan sangat 
diperlukan dalam rangka revitalisasi sektor pertanian. Sebagai suatu kepulauan yang terletak di daerah tropis, Indonesia memiliki faktor-faktor ekologis yang baik untuk membudidayakan tanaman perkebunan.

Kelapa merupakan salah satu komoditi subsektor perkebunan yang penting bagi Indonesia. Tumbuhan kelapa dimanfaatkan hampir semua bagiannya oleh manusia sehingga dianggap sebagai tanaman serba guna. Komoditas kelapa menjadi komoditas unggulan di Daerah Istimewa Yogyakarta (DIY) karena luas areal perkebunan di DIY didominasi oleh tanaman kelapa. Tidak kalah pentingnya mayang kelapa atau bunga kelapa juga dapat diambil cairan beningnya yang dinamakan nira. Nira kelapa ini dapat dimanfaatkan sebagai bahan baku untuk produksi gula semut.

DIY terdiri dari empat Kabupaten dan satu Kotamadya yaitu Kulon Progo, Bantul, Gunung Kidul, Sleman, dan Yogyakarta. Menurut Data Badan Pusat Statistik DIY Tahun 2017, Kabupaten Kulon Progo merupakan Kabupaten dengan luas tanam kelapa paling luas di DIY dengan luas 18.251,79 hektar. Kulon Progo memiliki dua belas kecamatan dimana salah satu mata pencaharian utama masyarakatnya yaitu di bidang pertanian dan perkebunan. Menurut Dinas Pertanian dan Pangan Kabupaten Kulon Progo (2017), Kecamatan Kokap memiliki luas tanam 820,50 hektar dengan produksi $1.538 .627 \mathrm{~kg}$.

Tanaman kelapa ini banyak dimanfaatkan masyarakat Kecamatan Kokap untuk disadap guna diolah menjadi berbagai produk salah satunya gula kelapa. Gula kelapa terbagi menjadi dua jenis yaitu gula merah (gula kelapa cetak) dan gula. Di Kulon Progo, gula semut menjadi salah satu produk unggulan yang bernilai ekonomis tinggi yang sudah menembus pasar internasional atau ekspor.
Gula semut mempunyai beberapa keunggulan dibandingkan dengan gula kelapa cetak, yaitu lebih praktis pemanfaatannya, lebih mudah larut, lebih lama daya simpannya, bentuknya lebih menarik, pengemasan dan pengangkutan lebih mudah, rasa dan aromanya lebih khas (Mustaufik et al., 2014).

Usaha gula semut di Kecamatan Kokap merupakan industri kecil menengah. Terdapat lima desa yang produktif menghasilkan gula semut di Kecamatan Kokap yaitu Desa Hargotirto, Desa Hargowilis, Desa Hargorejo, Desa Hargomulyo, dan Desa Kalirejo.

Berdasarkan Tabel 1 menunjukkan bahwa dari kelima desa di Kokap jumlah produksi gula semut tertinggi di Desa Hargotirto. Tingginya jumlah produksi gula semut tersebut menyebabkan gula semut yang beredar di pasaran semakin banyak sehingga dibutuhkan peranan pemasaran yang baik dan efisien. Analisis usaha pada industri gula semut di desa Hargotirto sangat penting bagi produsen dalam melaksanakan usahanya guna peningkatan pendapatan serta pengembangan usaha. Analisis pemasaran juga penting karena dengan pemasaran yang baik akan menghasilkan pendapatan atau nilai ekonomi yang tinggi pada produsen. Kenyataannya, seringkali produsen tidak memperhatikan manajemen usaha maupun pemasaran. Kendala dalam industri gula semut yatu kurangnya ketersediaan bahan baku untuk memenuhi proses produksi, penggunaan tenaga kerja yang banyak sehingga memperbesar biaya yang dikeluarkan, produsen masih sebagai price taker, dan juga saluran pemasaran yang panjang dalam pemasaran gula semut. Oleh karena itu diperlukan analisis usaha dan pemasaran dari produksi gula semut sehingga produsen dapat melihat perkembangan dari usahanya.

Tabel 1.Jumlah Produsen Industri Kecil Gula Semut Kecamatan Kokap Kabupaten Kulon Progo Tahun 2017

\begin{tabular}{clrrr} 
No. & Desa & Jumlah Produsen (orang) & Produksi $(\mathbf{k g})$ & Persentase (\%) \\
\hline 1. & Hargotirto & $\mathbf{1 . 3 8 4}$ & $\mathbf{1 . 0 7 4 . 1 7 3}$ & $\mathbf{6 3 , 3 2}$ \\
2. & Hargorejo & 264 & 73.889 & 4,36 \\
3. & Hargowilis & 1.520 & 304.530 & 17,95 \\
4. & Kalirejo & 659 & 159.329 & 9,39 \\
5. & Hargomulyo & 344 & 84.464 & 4,98 \\
\hline & Jumlah & $\mathbf{4 . 1 7 1}$ & $\mathbf{1 . 6 9 6 . 3 8 5}$ & $\mathbf{1 0 0 , 0 0}$ \\
\hline
\end{tabular}

Sumber: Dinas Perindustrian dan Perdagangan Kabupaten Kulon Progo, 2017 
Penelitian ini bertujuan untuk menganalisis pendapatan usaha gula semut, pola saluran pemasaran, biaya, keuntungan, marjin pemasaran, dan efisiensi secara ekonomi masing-masing saluran pemasaran yang digunakan produsen di Desa Hargotirto, Kecamatan Kokap, Kabupaten Kulon Progo.

\section{METODE PENELITIAN}

Metode dasar penelitian ini adalah metode deskriptif dengan teknik survei. Pemilihan lokasi dilakukan secara purposive di Desa Hargotirto, Kecamatan Kokap, Kabupaten Kulon Progo. Pemilihan lokasi berdasarkan jumlah produsen terbanyak di Kabupaten Kulon Progo dan produksi terbanyak di Kecamatan Kokap. Pengambilan jumlah responden produsen gula semut dengan rumus Slovin sehingga didapatkan 93 responden produsen. Pengambilan responden slauran pemasaran dengan metode snowball sampling. Metode analisis data yang digunakan dalam menganalisis analisis usaha secara matematis menurut Purwaningsih (2017) biaya total, penerimaan, dan pendapatan dirumuskan sebagai berikut

$\mathrm{TC}=\mathrm{TFC}+\mathrm{TVC}$

Dimana, TC adalah total cost atau biaya total yang dikeluarkan untuk produksi meliputi TFC atau total biaya tetap (Rp) dan TVC atau total biaya variabel $(\mathrm{Rp})$. Biaya total dinyatakan dalam rupiah $(\mathrm{Rp})$.

$\mathrm{TR}=\mathrm{Q} \times \mathrm{P}$

Dimana, TR adalah total revenue atau penerimaan dimana $\mathrm{Q}$ atau jumlah produksi gula semut $(\mathrm{kg})$ dikalikan dengan $\mathrm{P}$ atau harga jual gula semut $(\mathrm{Rp})$. Penerimaan dinyatakan dalam rupiah per $\mathrm{kg}(\mathrm{Rp} / \mathrm{kg})$.

$\pi=\mathrm{TR}-\mathrm{TC}$

Dimana, $\pi$ adalah pendapatan usaha gula semut (Rp), TR adalah penerimaan usaha gula semut (Rp), dan TC adalah biaya total usaha gula semut $(\mathrm{Rp})$.

Metode analisis untuk menganalisis pola pemasaran yaitu dengan metode deskriptif.
Biaya, keuntungan, marjin pemasaran, dan efisiensi pemasaran secara ekonomis dapat dirumuskan sebagai berikut.

$\mathrm{Bp}=\mathrm{B} \mathrm{p}_{1}+\mathrm{Bp}_{2}+\mathrm{Bp}_{3}+\ldots+\mathrm{B} \mathrm{p}_{1}$

Dimana, Bp adalah Biaya pemasaran (Rp) dan $\mathrm{Bp}_{1-\mathrm{n}}$ adalah biaya pemasaran pada tiap lembaga pemasaran $(\mathrm{Rp})$.

$\mathrm{Kp}=\mathrm{K} \mathrm{p}_{1}+\mathrm{Kp}_{2}+\mathrm{Kp}_{3}+\ldots+\mathrm{K} \mathrm{p}_{\mathrm{n}}$

Dimana, Kp adalah keuntungan pemasaran yang dinyatakan dalam rupiah ( $\mathrm{Rp}$ ) dan $\mathrm{Kp}_{1-\mathrm{n}}$ adalah keuntungan pemasaran pada tiap lembaga pemasaran $(\mathrm{Rp})$.

$\mathrm{M}=\mathrm{Pr}-\mathrm{Pf}$

$\mathrm{M}=\mathrm{Bp}+\mathrm{Kp}$

Dimana $\mathrm{M}$ adalah marjin pemasaran, Pr adalah harga ditingkat konsumen (Rp), Pf adalah harga di tingkat produsen (Rp), Bp adalah biaya pemasaran ( $\mathrm{Rp})$, dan $\mathrm{Kp}$ adalah keuntungan pemasaran (Rp), (Sudiyono, 2001).

$\mathrm{Mp}=\frac{\mathrm{P}_{r}-\mathrm{P} f_{f}}{\mathrm{Pr}_{r}} \times 100 \%$

Dimana $\mathrm{Mp}$ adalah persentase marjin pemasaran (\%), Pr adalah harga ditingkat konsumen (Rp), dan Pf adalah harga di tingkat produsen $(\mathrm{Rp})$.

$\mathrm{F}=\left(1-\frac{M}{P_{r}}\right) \times 100 \%$

Dimana $\mathrm{F}$ adalah farmer's share (\%), $\mathrm{M}$ adalah total marjin pemasaran, dan $\operatorname{Pr}$ adalah harga ditingkat konsumen (Rp).

\section{HASIL DAN PEMBAHASAN}

\section{Karakteristik Responden}

Tabel 2 menunjukkan bahwa rata-rata umur produsen gula semut di Desa Hargotirto yaitu 56 tahun. Umur ini masih termasuk dalam umur produktif. Pada umur produktif, produktivitas kerja produsen gula semut cukup tinggi sehingga lebih potensial dalam menjalankan usahanya.

Para produsen gula semut menempuh pendidikan formal di sekolah dengan rata-rata 
lama pendidikan yang ditempuh selama 9 tahun. Hal ini menunjukkan bahwa sebagian besar produsen sudah menduduki tingkat pendidikan SMP. Tingkat pendidikan yang ditempuh produsen, wawasan ataupun pengetahuan yang dimiliki produsen berpengaruh terhadap pola pikir produsen dalam pengambilan keputusan yang lebih rasional dalam menentukan strategi untuk usahanya.

Tabel 2. Identitas Responden Industri Gula Semut di Desa Hargotirto

\begin{tabular}{llr}
\hline No. & \multicolumn{1}{c}{ Uraian } & \multicolumn{2}{c}{$\begin{array}{l}\text { Rata- } \\
\text { rata }\end{array}$} \\
\hline 1. & Umur responden (tahun) & 56 \\
2. & Lama pendidikan formal (tahun) & 9 \\
3. & Pendidikan non formal (kali) & 5 \\
4. & Jumlah anggota keluarga(orang) & 3 \\
5. & Jumlah anggota keluarga yang & 2 \\
6. & aktif dalam produksi (orang) & 7 \\
\hline
\end{tabular}

Sumber: Analisis Data Primer, 2018

Produsen gula semut di Desa Hargotirto juga mendapatkan pendidikan non formal. Pendidikan non formal selama ini yang didapat seperti pelatihan branding, pelatihan pembuatan gula semut dengan menggunakan mesin, pelatihanpackaging, dan lain-lain.

Rata-rata jumlah anggota keluarga produsen gula semut di Desa Hargotirto yaitu sebanyak 3 orang. Jumlah rata-rata anggota keluarga yang aktif dalam proses produksi gula semut sebanyak 2 orang. Sebagian besar anggota keluarga yang aktif adalah suami dan istri. Anggota keluarga yang tidak aktif dalam proses produksi gula semut bekerja pada sektor lain atau termasuk dalam usia non produktif. Usaha gula semut di Desa Hargotirto rata-rata sudah berjalan selama 7 tahun. Hal ini menunjukkan bahwa produsen di Desa Hargotirto sudah cukup lama dalam menjalankan usahanya sehingga mereka memiliki cukup pengalaman dalam memproduksi gula semut.

\section{Biaya-biaya Industri Gula Semut di Desa Hargotirto}

Menurut Varian (2010), Antriyandarti (2012), McConnell et al. (2012), dan Syukur et al. (2015) biaya usaha dapat diklasifikasikan menjadi dua, yaitu biaya tetap (fixed cost) dan biaya variabel (variable cost). Biaya tetap adalah biaya yang relatif jumlahnya dan terus dikeluarkan walaupun produksi yang diperoleh banyak atau sedikit sehingga besarnya tidak tergantung pada besar kecilnya biaya produksi yang diperoleh. Biaya variabel adalah biaya yang besar kecilnya dipengaruhi oleh produksi yang diperoleh.

Tabel 3 menunjukkan bahwa besar ratarata biaya total yang dikeluarkan produsen gula semut sebesar Rp27.484,10 untuk satu kali produksi. Biaya terbesar dikeluarkan oleh biaya variabel sebesar Rp22.151,10 atau 80,60\%.

Tabel 3. Rata-rata Biaya Industri Gula Semut di Desa Hargotirto

\begin{tabular}{|c|c|c|c|}
\hline No. & Jenis Biaya & Rata-rata (Rp/satu kali produksi) & Persentase $(\%)$ \\
\hline \multirow[t]{4}{*}{1.} & Biaya Tetap & & \\
\hline & a. Biaya Penyusutan Peralatan & $5.333,20$ & 100,00 \\
\hline & b. Biaya Pajak Tanah & - & - \\
\hline & Jumlah & $5.333,20$ & 100,00 \\
\hline \multirow[t]{12}{*}{2.} & Biaya Variabel & & \\
\hline & a. Bahan Baku (liter) & $5.337,90$ & 24,10 \\
\hline & b. Bahan Penolong (kg) & 218,86 & 0,99 \\
\hline & - Kapur Gamping & 130,11 & \\
\hline & - Getah Manggis & 20,00 & \\
\hline & - Santan Kelapa & 68,75 & \\
\hline & c. Bahan Bakar $(\mathrm{kg})$ & $4.402,33$ & 19,87 \\
\hline & d. Pengemasan (pcs) & $1.500,00$ & 6,77 \\
\hline & e. Transportasi (Rp) & $2.083,13$ & 9,40 \\
\hline & f. Tenaga Kerja (jam) & $8.608,87$ & 38,86 \\
\hline & Jumlah & $22.151,10$ & 100,00 \\
\hline & Biaya Total & $27.484,30$ & 100,00 \\
\hline
\end{tabular}

Sumber: Analisis Data Primer, 2018 
Hal ini karena biaya variabel dipengaruhi oleh volume produksi dan tingginya harga dari bahan-bahan penunjang proses produksi seperti bahan baku, bahan penolong, bahan bakar, bahan pengemasan, tenaga kerja, dan trasnportasi. Produsen rata-rata mengeluarkan biaya tetap sebesar Rp5.333,20 untuk sekali produksi atau $19,40 \%$.

\section{Penerimaan dan Pendapatan Industri Gula Semut di Desa Hargotirto}

Penerimaanya itu perkalian antara jumlah produksi ( $\mathrm{kg}$ ) dengan harga jual ( $\mathrm{Rp}$ ) yang hasilnya dinyatakan dalam rupiah per $\mathrm{kg}$ $(\mathrm{Rp} / \mathrm{kg})$. Pendapatan adalah selisih antara penerimaan dan seluruh biaya yang dikeluarkan dalam sekali periode (Suratiyah, 2006).

Tabel 4. Rata-rata Penerimaan dan Pendapatan Industri Gula Semut di Desa Hargotirto

\begin{tabular}{lc}
\hline Uraian & $\begin{array}{l}\text { Rata-rata per satu } \\
\text { kali produksi }\end{array}$ \\
\hline Jumlah produksi $(\mathrm{kg})$ & 2,94 \\
Harga $(\mathrm{Rp} / \mathrm{kg})$ & $17.516,13$ \\
Penerimaan $(\mathrm{Rp})$ & $51.360,22$ \\
Biaya total (Rp) & $27.484,30$ \\
Pendapatan (Rp) & $23.875,92$ \\
\hline
\end{tabular}

Sumber: Analisis Data Primer, 2018

Tabel 4. menunjukkan bahwa rata-rata jumlah produksi gula semut sebanyak $2,94 \mathrm{~kg}$. Harga gula semut berfluktuasi tergantung cuaca. Pada saat musim penghujan harga cenderung rendah dibandingkan dengan saat musim panas. Rata-rata harga jual gula semut sebesar Rp17.516,13/kg. Dengan mengetahui rata-rata produksi dan harga dari gula semut dapat dihitung penerimaan yang didapatkan oleh produsen dalam satu kali produksi. Penerimaan yang diterima produsen gula semut di Desa Hargotirto yaitu sebanyak Rp51.360,22.

Pendapatan yang diterima produsen dalam satu kali produksi sebesar Rp23.875,92. Rata-rata biaya total yang dikeluarkan sebesar $\mathrm{Rp} 25.401,16$ dan penerimaan yang diterima setiap produsen gula semut dalam satu kali produksi sebesar Rp51.360,22. Pendapatan produsen diperoleh dengan mengurangi penerimaan yang diperoleh dengan biaya total .

\section{Karakteristik Responden Lembaga Pemasaran dan Konsumen Gula Semut}

Tabel 5. menunjukkan bahwa umur responden lembaga pemasaran masih dalam usia produktif yaitu pada umur 41-50 tahun. Tingkat pendidikan responden lembaga pemasaran sebagian besar menempuh seluruh tingkat pendidikan karena sebagian besar responden telah menempuh tingkat pendidikan SMA. Pengalaman usaha responden lembaga pemasaran paling banyak selama 1-10 tahun. Hal ini karena responden telah memiliki langganan sendiri dan konsumen yang terbentuk tanpa ada paksaan dari pedagang.

Jumlah konsumen terbanyak yang mengonsumsi gula semut berusia 21 sampai 30 tahun. Rata-rata konsumen telah menempuh pendidikan sampai tingkat SMA. Konsumen membeli gula semut memiliki beberapa alasan dalam melakukan pembelian karena ingin mencoba, ada juga yang dijadikan sebagai oleholeh.

\section{Saluran Pemasaran}

Saluran pemasaran adalah rangkaian lembagalembaga pemasaran yang dilalui dalam penyaluran gula semut dari produsen sampai ke konsumen. Dari hasil penelitian terdapat lima pola pemasaran, namun hanya tiga pola pemasaran yang di teliti dalam penelitian ini.

Dari hasil penelitian hanya tiga pola pemasaran yang diteliti. Hal ini karena pada saluran pemasaran II dan IV konsumen berada di luar kota yang bertentangan dengan pembatasan masalah yang hanya menganalisis pemasaran yang dibatasi pada Kabupaten Kulon Progo dan konsumen yang membeli dan mengonsumsi gula semut di Kabupaten Kulon Progo.

Biaya, Keuntungan, dan Marjin Pemasaran Kegiatan pemasaran gula semut dari produsen sampai ke konsumen membutuhkan biaya yang dikeluarkan untuk penyaluran produk sehingga harga yang dibayarkan kosumen lebih tinggi. Biaya pemasaran yang dikeluarkan dalam penelitian ini meliputi biaya transportasi, biaya pengemasan, dan biaya bongkar muat 
Mega N. A. P., Raden Kunto A., Isti Khomah: Analisis Usaha dan Pemasaran ...

Tabel 5. Karakteristik Responden Pedagang dan Konsumen dalam Pemasaran Gula Semut di Desa Hargotirto, Kecamatan Kokap, Kabupaten Kulon Progo

\begin{tabular}{|c|c|c|c|}
\hline $\mathrm{No}$ & Uraian & Jumlah & Presentase (\%) \\
\hline \multirow[t]{19}{*}{1.} & Pedagang & & \\
\hline & Umur & - & - \\
\hline & a. $21-30$ & 7 & 38,89 \\
\hline & b. $31-40$ & 6 & 33,33 \\
\hline & c. $41-50$ & 5 & 27,78 \\
\hline & d. $\quad 51-60$ & - & - \\
\hline & e. $>60$ & & \\
\hline & Total & 18 & 100,00 \\
\hline & Pendidikan & & \\
\hline & a. Tidak Sekolah & - & - \\
\hline & b. SD & 3 & 16,67 \\
\hline & c. SMP & 7 & 38,89 \\
\hline & d. SMA & 6 & 33,33 \\
\hline & e. Perguruan Tinggi & 2 & 11,11 \\
\hline & Total & 18 & 100,00 \\
\hline & $\begin{array}{l}\text { Pengalaman Usaha } \\
\text { (Tahun) }\end{array}$ & & \\
\hline & a. $1-10$ & 13 & 72,22 \\
\hline & b. $11-20$ & 5 & 27,78 \\
\hline & Total & 18 & 100,00 \\
\hline \multirow[t]{15}{*}{2.} & Konsumen & & \\
\hline & Umur & & \\
\hline & a. $21-30$ & 14 & 51,85 \\
\hline & b. $\quad 31-40$ & 4 & 14,81 \\
\hline & c. $41-50$ & 7 & 25,93 \\
\hline & d. $\quad 51-60$ & 2 & 7,41 \\
\hline & e. $>60$ & - & - \\
\hline & Total & 27 & 100,00 \\
\hline & Pendidikan & & \\
\hline & a. Tidak Sekolah & - & - \\
\hline & b. SD & 1 & 3,70 \\
\hline & c. SMP & 8 & 29,63 \\
\hline & d. SMA & 13 & 48,15 \\
\hline & e. Perguruan Tinggi & 5 & 18,52 \\
\hline & Total & 27 & 100,00 \\
\hline
\end{tabular}

Sumber: Analisis Data Primer, 2018

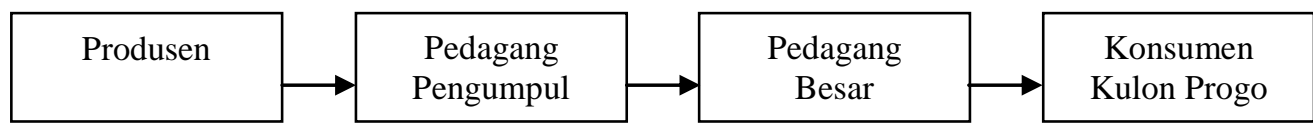

Gambar 1. Bagan Saluran Pemasaran I Gula Semut di Desa Hargotirto, Kecamatan Kokap, Kulon Progo

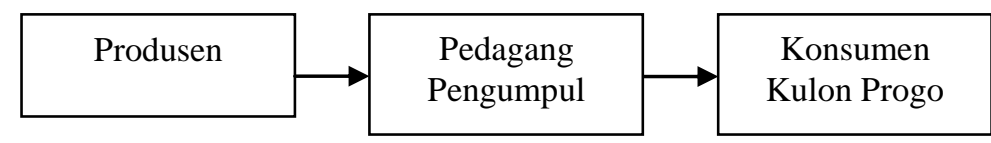

Gambar 2. Bagan Saluran Pemasaran III Gula Semut di Desa Hargotirto, Kecamatan Kokap, Kulon Progo

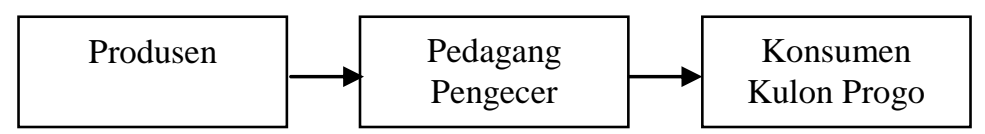

Gambar 3. Bagan Saluran Pemasaran V Gula Semut di Desa Hargotirto, Kecamatan Kokap, Kulon Progo 
Tabel 6. Rata-rata Biaya, Keuntungan, dan Marjin Pemasaran Gula Semut di Kabupaten Kulon Progo Pada Saluran Pemasaran I

\begin{tabular}{|c|c|c|c|}
\hline No & Uraian & Rp/kg & $\%$ \\
\hline \multirow[t]{15}{*}{1.} & Produsen & & \\
\hline & a. Harga Jual & $17.363,64$ & 72,35 \\
\hline & b. Biaya Bahan Baku & $6.054,55$ & 25,23 \\
\hline & c. Biaya Pengolahan & & \\
\hline & - $\quad$ Biaya Kapur Gamping & 154,55 & 0,64 \\
\hline & - $\quad$ Biaya Getah Manggis & 20,00 & 0,08 \\
\hline & - $\quad$ Biaya Santan & 68,75 & 0,29 \\
\hline & - Biaya Bahan Bakar & $4.217,57$ & 17,57 \\
\hline & Jumlah Biaya Pengolahan & $4.460,87$ & 18,59 \\
\hline & d. Harga Pokok Produksi & $10.515,42$ & 43,81 \\
\hline & e. Biaya Pemasaran & & \\
\hline & - Transportasi & 924,55 & 3,85 \\
\hline & - $\quad$ Pengemasaran & $1.500,00$ & 6,25 \\
\hline & Jumlah Biaya Pemasaran & $2.425,55$ & 10,11 \\
\hline & f. Keuntungan Produsen & $4.423,68$ & 18,43 \\
\hline \multirow[t]{10}{*}{2.} & Pedagang Pengumpul & & \\
\hline & a. Harga Beli & $17.363,64$ & 72,35 \\
\hline & b. Biaya Pemasaran & & \\
\hline & - Transportasi & 279,18 & 1,16 \\
\hline & - Pengemasan & $1.500,00$ & 6,25 \\
\hline & - $\quad$ Biaya Bongkar Muat & 150,00 & 0,63 \\
\hline & Jumlah Biaya Pemasaran & $1.929,18$ & 8,04 \\
\hline & c. Harga Jual & $20.272,73$ & 84,47 \\
\hline & d. Keuntungan Pemasaran & 979,91 & 4,08 \\
\hline & e. Marjin Pemasaran & $2.909,09$ & 12,12 \\
\hline \multirow[t]{10}{*}{3.} & Pedagang Besar & & \\
\hline & a. Harga Beli & $20.272,73$ & 84,47 \\
\hline & b. Biaya Pemasaran & & \\
\hline & - Transportasi & - & - \\
\hline & - Pengemasan & $1.490,48$ & 6,21 \\
\hline & - $\quad$ Biaya Bongkar Muat & - & - \\
\hline & Jumlah Biaya Pemasaran & $1.490,48$ & 9,89 \\
\hline & c. Harga Jual & $24.000,00$ & 100,00 \\
\hline & d. Keuntungan Pemasaran & $2.236,80$ & 5,64 \\
\hline & e. Marjin Pemasaran & $3.727,27$ & 11,85 \\
\hline \multirow[t]{2}{*}{4.} & Konsumen & & \\
\hline & Harga Beli Konsumen & $24.000,00$ & 100,00 \\
\hline \multirow[t]{5}{*}{5.} & Total Pemasaran & & \\
\hline & a. Total Biaya Pemasaran & $5.845,21$ & \\
\hline & b. Total Keuntungan Pemasaran & $7.640,39$ & \\
\hline & c. Total Marjin Pemasaran & $6.636,36$ & 27,65 \\
\hline & d. Farmer's Share & & 72,35 \\
\hline
\end{tabular}

Sumber: Analisis Data Primer, 2018

Berdasarkan Tabel 6. biaya pemasaran yang dikeluarkan produsen sebesar Rp2.425,55. Keuntungan yang diterima produsen gula semut yaitu sebesar Rp4.423,68. Produsen menjual gula semut kepada pedagang pengumpul. Dalam penjualan gula semut, pedagang pengumpul mengeluarkan biaya untuk melakukan pemasaran. Biaya ini meliputi biaya transportasi, biaya pengemasan, dan biaya bongkar muat. Total biaya yang dikeluarkan pedagang pengumpul untuk pemasaran gula semut yaitu Rp1.929,18. Kemudian pedagang pengumpul menjual gula semut kepada pedagang besar dengan harga Rp20.272,73. Biaya pemasaran di tingkat pedagang besar yaitu meliputi biaya transportasi, biaya pengemasan, dan biaya bongkar muat. Pada penelitian ini pedagang besar tidak mengeluarkan biaya transportasi maupun bongkar muat hal ini karena pedagang 
Tabel 7. Rata-rata Biaya, Keuntungan, dan Marjin Pemasaran Gula Semut di Kabupaten Kulon Progo Pada Saluran Pemasaran III

\begin{tabular}{|c|c|c|c|}
\hline No. & Uraian & Rp/kg & $\%$ \\
\hline \multirow[t]{15}{*}{1.} & Produsen & & \\
\hline & a. Harga Jual & $17.714,29$ & 77,99 \\
\hline & b. Biaya Bahan Baku & $5.812,50$ & 25,59 \\
\hline & c. Biaya Pengolahan & & \\
\hline & - Biaya Kapur Gamping & 142,86 & 0,63 \\
\hline & - $\quad$ Biaya Getah Manggis & 20,00 & 0,09 \\
\hline & - Biaya Santan & 68,75 & 0,30 \\
\hline & - Biaya Bahan Bakar & $3.530,48$ & 15,54 \\
\hline & Jumlah Biaya Pengolahan & $3.762,08$ & 16,56 \\
\hline & d. Harga Pokok Produksi & $9.996,01$ & 44,01 \\
\hline & e. Biaya Pemasaran & & \\
\hline & - Transportasi & $1.324,29$ & 5,83 \\
\hline & - $\quad$ Pengemasaran & $1.500,00$ & 6,60 \\
\hline & Jumlah Biaya Pemasaran & $2.824,29$ & 12,43 \\
\hline & f. Keuntungan Produsen & $4.893,99$ & 21,55 \\
\hline \multirow[t]{10}{*}{2.} & Pedagang Pengumpul & & \\
\hline & a. Harga Beli & $17.714,29$ & 77,99 \\
\hline & b. Biaya Pemasaran & & \\
\hline & - Transportasi & 92,86 & 0,41 \\
\hline & - $\quad$ Pengemasan & $2.414,71$ & 10,63 \\
\hline & - Biaya Bongkar Muat & 42,86 & 0,19 \\
\hline & Jumlah Biaya Pemasaran & $2.550,43$ & 11,23 \\
\hline & c. Harga Jual & $22.714,29$ & 100,00 \\
\hline & d. Keuntungan Pemasaran & $2.449,57$ & 10,78 \\
\hline & f. Marjin Pemasaran & $5.000,00$ & 22,01 \\
\hline \multirow[t]{2}{*}{3.} & Konsumen & & \\
\hline & Harga Beli Konsumen & $22.714,29$ & 100,00 \\
\hline \multirow[t]{5}{*}{4.} & Total Pemasaran & & \\
\hline & a. Total Biaya Pemasaran & $5.374,72$ & \\
\hline & b. Total Keuntungan Pemasaran & $7.343,56$ & \\
\hline & c. Total Marjin Pemasaran & $5.000,00$ & 22,01 \\
\hline & d. Farmer's Share & & 77,99 \\
\hline
\end{tabular}

Sumber: Analisis Data Primer, 2018

pengumpul sendiri yang menyetorkan gula semut ke tempat pedagang besar. Pengemasan oleh pedagang besar disesuaikan oleh permintaan konsumen.

Tabel 7. Menunjukkan bahwa biaya pemasaran yang dikeluarkan produsen meliputi biaya pengemasan $\mathrm{Rp} 1.500,00$ dan biaya transportasi Rp1324,29. Produsen menjual gula semut kepada pedagang pengumpul dengan harga $\mathrm{Rp} 17.714,29$ per $\mathrm{kg}$ sehingga produsen memperoleh keuntungan sebesar Rp4.893,99 per $\mathrm{kg}$. Pedagang pengumpul mengeluarkan biaya pemasaran untuk biaya pengemasan, biaya transportasi, dan biaya bongkar muat. Dengan harga jual kepada konsumen $\mathrm{Rp} 22.714,29$ per $\mathrm{kg}$ pedagang pengumpul memperoleh keuntungan sebesar Rp2.449,57. Total biaya pemasaran dalam saluran III yaitu Rp5.374,72, total keuntungan pemasaran
Rp7.343,56, total marjin pemasaran Rp5.000,00 dengan persentase marjin pemasaran sebesar 22,01\%, dan farmer's share sebesar 77,99\%. Nilai farmer's share sebesar $77,99 \%$ berarti bahwa bagian yang diterima produsen sebesar 77,99\% atau Rp17.714,29 dari harga yang diterima konsumen sebesar Rp22.714,29.

Tabel 8. Menunjukkan bahwa produsen menjual gula semut kepada pedagang pengecer dengan harga Rp17.363,64 per kg. Pedagang pengecer menjual kembali gula semut kepada konsumen dengan harga Rp22.204,55 per kg. Dalam penjualannya, pedagang pengumpul mengeluarkan biaya untuk pengemasan. Pengemasan yang dilakukan pedagang pengecer yaitu dengan menggunakan plastik putih. 
Tabel 8. Rata-rata Biaya, Keuntungan, dan Marjin Pemasaran Gula Semut di Kabupaten Kulon Progo Pada Saluran Pemasaran V

\begin{tabular}{|c|c|c|c|}
\hline No. & Uraian & Rp/kg & $\%$ \\
\hline \multirow[t]{15}{*}{1.} & Produsen & & \\
\hline & a. Harga Jual & $17.363,64$ & 78,20 \\
\hline & b. Biaya Bahan Baku & $4.295,45$ & 19,34 \\
\hline & c. Biaya Pengolahan & & \\
\hline & - Biaya Kapur Gamping & 136,36 & 0,61 \\
\hline & - $\quad$ Biaya Getah Manggis & 20,00 & 0,09 \\
\hline & - $\quad$ Biaya Santan & 68,75 & 0,31 \\
\hline & - Biaya Bahan Bakar & $4.315,30$ & 19,43 \\
\hline & Jumlah Biaya Pengolahan & $4.540,42$ & 20,45 \\
\hline & d. Harga Pokok Produksi & $8.835,87$ & 39,79 \\
\hline & e. Biaya Pemasaran & & \\
\hline & - Transportasi & 544,09 & 2,45 \\
\hline & - $\quad$ Pengemasaran & $1.500,00$ & 6,76 \\
\hline & Jumlah Biaya Pemasaran & $2.044,09$ & 9,21 \\
\hline & f. Keuntungan Produsen & $6.483,68$ & 29,20 \\
\hline \multirow[t]{10}{*}{2.} & Pedagang Pengecer & & \\
\hline & a. Harga Beli & $17.363,64$ & 78,20 \\
\hline & b. Biaya Pemasaran & & \\
\hline & - Transportasi & - & - \\
\hline & - Pengemasan & $1.363,64$ & 6,14 \\
\hline & - $\quad$ Biaya Bongkar Muat & - & - \\
\hline & Jumlah Biaya Pemasaran & $1.363,64$ & 6,14 \\
\hline & c. Harga Jual & $22.204,55$ & 100,00 \\
\hline & d. Keuntungan Pemasaran & $3.477,27$ & 15,66 \\
\hline & g. Marjin Pemasaran & $4.840,91$ & 21,80 \\
\hline \multirow[t]{2}{*}{3.} & Konsumen & & \\
\hline & Harga Beli Konsumen & $22.204,55$ & 100,00 \\
\hline \multirow[t]{5}{*}{4.} & Total Pemasaran & & \\
\hline & a. Total Biaya Pemasaran & $3.407,73$ & \\
\hline & b. Total Keuntungan Pemasaran & $9.960,95$ & \\
\hline & c. Total Marjin Pemasaran & $4.840,91$ & 21,80 \\
\hline & d. Farmer's Share & & 78,20 \\
\hline
\end{tabular}

Total biaya pemasaran pada saluran $\mathrm{V}$ sebesar Rp3.407,73 per kg, total keuntungan pemasaran Rp9.960,95 per $\mathrm{kg}$, total marjin pemasaran Rp4.840,91 dengan nilai persentase marjin pemasaran sebesar $21,80 \%$, dan nilai farmer's share sebesar 78,20\%. Nilai farmer's share ini berarti bahwa bagian yang diterima produsen sebesar 78,30\% atau sebesar Rp17.363,64.

\section{Efisiensi Pemasaran Secara Ekonomis}

Suatu pemasaran dapat dikatakan efisien apabila mampu menekan biaya-biaya pemasaran yang dikeluarkan dalam proses penyampaian produk dari produsen sampai kepada konsumen. Efisiensi pemasaran secara ekonomi adalah efisiensi pemasaran yang diukur dari besarnya marjin pemasaran dan bagian yang diterima produsen (farmer's share) dinyatakan dalam persen. Bila bagian yang diterima produsen $<50 \%$ dan marjin pemasaran $>50 \%$ berarti pemasaran belum efisien dan bila bagian yang diterima produsen $>50 \%$ dan marjin pemasaran $<50 \%$ maka pemasaran dikatakan efisien.

Untuk mengetahui tingkat efisiensi pemasaran gula semut secara ekonomis dapat dilihat dari besarnya persentase marjin pemasran dan farmer's share. Tabel 9. menunjukkan bahwa saluran pemasaran I memiliki nilai farmer's share terendah yang ada dalam pola saluran pemasaran. Pada saluran pemasaran $\mathrm{V}$ memiliki nilai farmer's share tertinggi dalam pola saluran pemasaran yang diteliti di Kabupaten Kulon Progo. 
Mega N. A. P., Raden Kunto A., Isti Khomah: Analisis Usaha dan Pemasaran ...

Tabel 9. Total Biaya, Total Keuntungan, Total Marjin Pemasaran, dan Farmer's Share Dari Ketiga Saluran Pemasaran Gula Semut di Kabupaten Kulon Progo

\begin{tabular}{lrrr}
\hline \multicolumn{1}{c}{ Uraian } & Saluran I & \multicolumn{1}{c}{ Saluran III } & \multicolumn{1}{c}{ Saluran V } \\
\hline a. Total Biaya (Rp/kg) & $5.845,21$ & $5.374,72$ & $3.407,73$ \\
b. Total Keuntungan (Rp/kg) & $7.640,39$ & $7.343,56$ & $9.960,95$ \\
c. Total Marjin Pemasaran (Rp/kg) & $6.636,36$ & $5.000,00$ & $4.840,91$ \\
d. Persentase Marjin Pemasaran (\%) & 27,65 & 22,01 & 21,80 \\
e. Farmer's Share $(\%)$ & 72,35 & 77,99 & 78,20 \\
\hline
\end{tabular}

Sumber: Analisis Data Primer, 2018

Pemasaran gula semut dapat dikatakan efisien apabila nilai persentase marjin pemasaran terendah dan nilai farmer's share tertinggi dan di atas 50\%. Berdasarkan hal tersebut dapat diketahui bahwa saluran pemasaran gula semut di Kabupaten Kulon Progo yang paling efisien adalah saluran pemasaran V. Hal ini disebabkan saluran pemasaran $\mathrm{V}$ memiliki saluran pemasaran yang pendek, nilai persentase marjin pemasaran terendah sebesar $21,80 \%$, dan nilai farmer's share di atas $50 \%$ dan tertinggi dari semua pola saluran pemasaran yang diteliti di Kabupaten Kulon Progo.

\section{KESIMPULAN DAN SARAN}

Berdasarkan hasil penelitian analisis usaha dan pemasaran di Desa Hargotirto, Kecamatan Kokap, Kabupaten Kulon Progo dapat ditarik kesimpulan sebagai berikut (1)Rata-rata biaya total usaha gula semut di Desa Hargotirto, Kecamatan Kokap, Kabupaten Kulon Progo Rp25.401,16 per satu kali produksi, rata-rata penerimaan usaha yang diperoleh produsen sebesar Rp51.366,22 per satu kali produksi sehingga rata-rata pendapatan yang diterima produsen gula semut sebesar Rp25.959,05 per satu kali produksi; (2) Dalam pemasaran gula semut di Kabupaten Kulon Progo terdapat tiga saluran pemasaran yang diteliti yaitu saluran pemasaran I: $\quad$ Produsen $\rightarrow$ Pedagang Pengumpul $\rightarrow$ Pedagang $\quad$ Besar $\rightarrow$ Kosumen, saluran pemasaran III: Produsen $\rightarrow$ Pedagang Pengumpul $\rightarrow$ Konsumen, saluran pemasaran $\mathrm{V}:$ Produsen $\rightarrow$ Pedagang Pengecer $\rightarrow$ Konsumen; (3) Biaya pemasaran pada saluran pemasaran I sebesar Rp5.845,21 per kg, saluran pemasaran III sebesar Rp5.374,72 per $\mathrm{kg}$, dan saluran pemasaran V sebesar Rp3.407,73 per kg. Keuntungan pemasaran pada saluran pemasaran I sebesar Rp7.343,56 per kg, pada saluran pemasaran III sebesar Rp7.343,56 per $\mathrm{kg}$, dan pada saluran pemasaran $\mathrm{V}$ sebesar Rp9.960,95. Marjin pemasaran yang diperoleh pada saluran pemasaran I sebesar Rp6.636,36 per $\mathrm{kg}$, saluran pemasaran III sebesar Rp5.000,00 per kg, dan pada saluran pemasaran V sebesar Rp4.840,91 per kg; (4) Di dalam pemasaran gula semut di Kabupaten Kulon Progo, saluran pemasaran V memiliki saluran yang lebih pendek, efisiensi pemasaran secara ekonomi paling efisien dibandingkan saluran pemasaran I dan saluran pemasaran III karena memiliki nilai farmer's share paling tinggi yaitu $78,20 \%$ dan nilai persentase marjin pemasaran paling rendah yaitu $21,80 \%$.

Berdasarkan hasil penelitian, maka saran yang dapat diberikan demi kemajuan usaha gulasemut di Desa Hargotirto antara lain (1) Untuk meningkatkan pendapatan usaha, produsen gula semut sebaiknya melakukan inovasi pengemasan yaitu dengan melakukan variasi kemasan (kardus atau paperbag) dan pemberian label (nama, alamat, serta nomor telepon yang bisa dihubungi) sehingga lebih menarik konsumen; (2) Terdapat tiga pola saluran pemasaran yang diteliti di Kabupaten Kulon Progo, dimana saluran pemasaran V merupakan saluran yang paling efisien karena memiliki saluran yang lebih pendek, nilai persentase marjin pemasaran terendah, dan nilai farmer's share tertinggi. Namun, terdapat $53,19 \%$ produsen memilih memasarkan produknya ke pedagang pengumpul atau saluran I dan III karena adanya keterikatan diantara kedua pihak. Oleh karena itu, perlu adanya bantuan dari Dinas Perdagangan untuk memberikan penyuluhan kepada produsen agar lebih tepat dalam memilih saluran pemasaran yang lebih menguntungkan. 


\section{DAFTAR PUSTAKA}

Antriyandarti, E. 2012. Ekonomika Mikro untuk Ilmu Pertanian. Yogyakarta: Nuha Litera.

BPS. 2017. Luas Tanam Kelapa di DiY Tahun 2016. Yogyakarta: Badan Pusat Statistik DIY.

DPP. 2107. Luas Tanam, Luas Panen, dan Produksi Komoditas Kelapa di setiap Kecamatan Kabupaten Kulon Progo Tahun 2017. Kulon Progo: Dinas Pertanian dan Pangan Kabupaten Kulon Progo.

McConnell, C.R., Brue, S.L., Flynn, S.M. and Grant, R. 2012. Economics: Principles, Problems, and Policies. 19th ed. New York: McGraw-Hill.

Mustaufik, Tobari, dan Nurul, H. 2014. Peningkatan Mutu Produksi dan
Pemasaran Gula Semut Beriodium di Koperasi Serba Usaha (KSU) Ligasirem Sumbang - Banyumas. Jurnal Performance, 19(1): 68-84.

Purwaningsih, Y. 2017. Ekonomi Pertanian Pendekatan Teori, Kebijakan, dan Penerapan. Surakarta: UNS Press.

Sudiyono. 2001. Pemasaran Pertanian. Malang: UMM Pers.

Suratiyah, K. 2006. Ilmu Usahatani. Jakarta: Penebar Swadaya.

Syukur, M., Helfi, E.S., dan Rudy, H. 2015. Bertanam Tomat di Musim Hujan. Jakarta: Penebar Swadaya Grup.

Varian, H. R. 2010. Intermediate microeconomics: A modern approach. New York: W.W. Norton \& Co. 